\title{
Estado de los micronutrientes hierro y vitamina $A$, factores de riesgo para las deficiencias y valoración antropométrica en niños preescolares del municipio de Funza, Colombia
}

\author{
Elpidia Poveda, Alexandra Cuartas, Saralicia Guarín, Yibby Forero, Elsa Villarreal. \\ Grupo de Nutrición, Subdirección de Investigación, Instituto Nacional de Salud, Bogotá D.C., Colombia. \\ Introducción. La malnutrición y las deficiencias de hierro y vitamina A son frecuentes en la \\ población colombiana y están asociadas con factores de riesgo biológicos y ambientales. \\ Objetivo. Determinar la prevalencia de anemia, la deficiencia de hierro y vitamina A y el estado \\ nutricional por antropometría en niños preescolares del municipio de Funza; identificar la \\ asociación entre la deficiencia de micronutrientes y los factores de riesgo para estas deficiencias \\ reportados en la literatura. \\ Materiales y métodos. Estudio descriptivo en 287 preescolares mediante valoración \\ antropométrica, bioquímica de concentraciones sanguíneas de hemoglobina, ferritina y vitamina \\ A y examen coprológico. Por encuesta se investigó sobre algunos de los factores de riesgo \\ para estas deficiencias. \\ Resultados. El 40,8\% de los preescolares tenía anemia; el 5,2\%, deficiencia de hierro, y el \\ $4,6 \%$, deficiencia de vitamina A; además, se encontraron preescolares con desnutrición. Se \\ encontró asociación entre las concentraciones bajas de hemoglobina, vivir en inquilinato y no \\ ser beneficiario de algún programa nutricional; también hubo asociación entre la deficiencia \\ de vitamina $A$ y el riesgo de adquirirla con morbilidad sentida en el último mes. Aunque sin \\ asociación estadística, se identificó una alta frecuencia de otros factores de riesgo para las \\ deficiencias de los micronutrientes. \\ Conclusión. Existe la necesidad de fortalecer programas fundamentados en las condiciones \\ existentes para mejorar la situación nutricional de los preescolares del municipio de Funza. Es \\ importante indagar si se presenta anemia nutricional relacionada con ácido fólico y vitamina \\ $\mathrm{B}_{12}$, así como sobre otros factores de riesgo asociados con la deficiencia nutricional por hierro \\ y vitamina $A$.
}

Palabras clave: deficiencia de hierro, anemia, deficiencia de vitamina A, factores de riesgo, antropometría, preescolares.

Iron and vitamin A micronutrient status, risk factors for their deficiencies and anthropometric assessment in preschool child from Funza municipality, Colombia

Introduction. The malnutrition and deficiencias of iron and vitamin A are frequent in the Colombian population and are associated with biological and environmental risk factors.

Objective. Prevalence of anemia, iron and vitamin A deficiencies and nutritional status was determined by anthropometric assessment in a population of preschool children in the municipality of Funza. Associations were made between micronutrient deficiency and other risk factors reported in the literature.

Materials and methods. The nutrition status of 287 child preschool was assessed by means of anthropometric evaluation, levels of hemoglobin, ferritin, and vitamin A in blood sera, in addition to fecal examination. A survey was administered to identify risk factors associated with these deficiencies.

Results. Of these children, $40.8 \%$ showed anemia, $5.2 \%$ iron deficiency and $4.6 \%$ vitamin $A$ deficiency. In addition, the children were generally malnourished. Significant associations were noted between low levels of hemoglobin, rented housing, lack of a nutritional program, low levels of vitamin A, and illness in the previous month. Nonsignificant, but statistical association was observed with other risk factors. 
Conclusion. Incentive programs are necessary to improve the nutritional situation of the preschool children from Funza municipality, Colombia. Nutritional status can be determined by examination of levels of folic acid, vitamin B12, iron and vitamin A in association with social risk factors.

Key words: Iron deficiency, anemia, vitamin A deficiency, risk factors, anthropometry, preschool children.

En algunos grupos de población se presentan deficiencias de micronutrientes (vitaminas y minerales) y malnutrición proteico calórica que ocasionan alteraciones fisiológicas que afectan el estado de salud de los individuos; estas deficiencias también tienen repercusiones sociales, entre ellas, la disminución de la capacidad laboral (1-6).

La deficiencia de vitamina A se encuentra principalmente en lactantes y niños preescolares y es una de las causas de muerte en los países en desarrollo. Se asocia a enfermedades respiratorias y diarreicas y aumenta la frecuencia, gravedad y mortalidad en casi todas las enfermedades infecciosas (2). La deficiencia primaria se acompaña de queratinización en membranas mucosas, piel y epitelio ocular, disminuyendo el mecanismo de barrera contra infecciones; a largo plazo produce ceguera nocturna y ulceraciones de la cornea, inhibición del apetito, pérdida del sentido del gusto e inhibición del crecimiento (2).

La anemia por deficiencia de hierro (ferropénica) es uno de los problemas nutricionales más frecuentes en la población y se desarrolla en tres estadios. En el primero se agotan las formas de depósito de hierro (ferritina y hemosiderina); el segundo se manifiesta por una disminución en los niveles de saturación de transferrina hasta menos de $15 \%$, siendo inadecuado el abastecimiento del hierro para producir eritrocitos en la médula ósea; asimismo, hay disminución de la hemoglobina que origina micrositosis e hipocromía.

\footnotetext{
Correspondencia:

Elpidia Poveda Espinosa, Grupo de Nutrición, Subdirección de Investigación, Instituto Nacional de Salud, Av Calle 26 No. 51-60, Zona 6 CAN.

Teléfono: 2207700 extensión 303, fax 2207700 extensión 255/ 310

epoveda1@yahoo.com, epoveda@ins.gov.co

Recibido:16/08/06; aceptado: 15/12/06
}

En el tercer estadio se genera anemia franca con descenso de la hemoglobina hasta niveles que dan lugar a una reducción de su concentración por debajo de los valores de referencia para las personas de la misma edad y sexo $(1,6,7)$.

Las manifestaciones funcionales por deficiencia de hierro dependen del grado de depleción. Algunas consecuencias son retardo del crecimiento, alteraciones en el desarrollo mental y psicomotor, déficit en la capacidad activa de aprendizaje, dificultad para mantener la concentración y aumento del riesgo de infecciones. Se presenta disminución de la eficiencia en el trabajo y de la capacidad física, razón por la que la productividad y los ingresos económicos de los trabajadores es menor en poblaciones anémicas (6). Lo anterior implica altos costos para la salud pública y pérdidas en el producto interno bruto por vidas perdidas, discapacidad y menor productividad (4). Entre los grupos más vulnerables se encuentran los niños menores de dos años, las niñas adolescentes, las gestantes y los adultos mayores $(8,9)$.

Algunos de los factores de riesgo para deficiencia de hierro y vitamina $A$ se relacionan con la composición familiar, la distribución intrafamiliar, la calidad y el manejo de los alimentos, la localización geográfica $(2,10-16)$, y las prácticas incorrectas de lactancia materna y de preparación de alimentos en el destete $(12,17,18)$, así como con la baja escolaridad de los padres $(11,18-20)$, el hacinamiento y los bajos ingresos (10). No obstante, otros autores concluyen que la baja ingesta de hierro y vitamina $A$ se presenta en todos los grupos socioeconómicos (21). Otros factores asociados son las infecciones crónicas o recurrentes, la infección por parásitos, la baja ingesta de alimentos fuente de hierro y vitamina $A$, el género y los hábitos y creencias que suscitan disminución de las concentraciones de hierro y vitamina A $(12-14,16,18,19,22-28,29,30)$. Las 
deficiencias de vitamina A y hierro se asocian, además, a la malnutrición proteico energética $(27,29,30)$.

La Encuesta Nacional de Demografía y Salud, ENDS 2005, y la Encuesta Nacional de la Situación Nutricional en Colombia, ENSIN 2005, determinaron que $12 \%$ de los niños menores de cinco años presentaron desnutrición crónica y $7 \%$, bajo peso para la edad ( $6 \%$, moderado y $1 \%$, grave). La prevalencia de la desnutrición por bajo peso para la estatura se presentó en $1 \%$ de los niños y fue básicamente de carácter moderado $(31,32)$. En cuanto a la anemia, la prevalencia en menores de cinco años fue de $33,2 \%$, la deficiencia de hierro de $12,5 \%$ y la deficiencia de vitamina A de 5,9\%. En el municipio de Funza, Cundinamarca, no se encontraron estudios publicados sobre el estado nutricional y la deficiencia de micronutrientes en preescolares.

El objetivo de este estudio fue determinar la prevalencia de anemia y la deficiencia de hierro y vitamina $A$, e identificar el estado nutricional por antropometría en niños de dos a cinco años del municipio de Funza que asisten a las instituciones educativas del municipio o a Hogares Comunitarios del Instituto Colombiano de Bienestar Familiar (ICBF); adicionalmente, establecer si en esta población existe asociación entre la deficiencia de micronutrientes y algunos factores de tipo biológico y de medio ambiente reportados en la literatura como de riesgo para desarrollar la deficiencia.

\section{Materiales y métodos}

\section{Tipo de estudio y muestra}

El estudio fue de tipo transversal, descriptivo, en niños de dos a cinco años de edad asistentes a instituciones educativas públicas o privadas y Hogares Comunitarios del ICBF del área urbana y rural del Municipio de Funza, departamento de Cundinamarca, Colombia.

Se tomó una muestra probabilística por conglomerados y estratificada constituida por 287 niños de dos a cinco años residentes en el área urbana y rural de Funza. La muestra se calculó con un error de estimación del $6 \%$ y una pérdida del $10 \%$. El marco de muestreo se conformó a partir de los registros de los niños que asisten a colegios o jardines oficiales o privados, o a Hogares Comunitarios del ICBF de la zona urbana y rural del municipio.

\section{Proceso metodológico}

Prueba piloto. Se realizó una prueba piloto en la que se aplicó y validó la encuesta y el cuestionario de frecuencia de consumo de alimentos. Se verificó la inclusión de las variables de interés, la correcta aplicación y formulación de la pregunta, el tiempo y la facilidad para el diligenciamiento del formulario. Posteriormente se hicieron los ajustes correspondientes a la encuesta.

Variables bioquímicas. Bacteriólogas del Grupo de Nutrición del Instituto Nacional de Salud recolectaron una muestra de $5 \mathrm{ml}$ de sangre total mediante la técnica de punción venosa. La recolección se realizó siguiendo los procedimientos operativos estándar de recolección y procesamiento de muestras del Laboratorio de Nutrición del Instituto Nacional de Salud, los cuales siguen los estándares internacionales para este procedimiento (33). A partir de estas muestras se analizaron los siguientes indicadores bioquímicos.

Hemoglobina: se evaluó usando el sistema de HemoCue que está constituido por un fotómetro sencillo y microcubetas con reactivos secos. Como valores referencia para clasificar la hemoglobina se tomaron los recomendados por la Organización Mundial de la Salud (OMS). EI punto de corte para definir anemia en niños de uno a cuatro años es de $11,0 \mathrm{~g} / \mathrm{dl}$ y para niños de cinco años de $11,5 \mathrm{~g} / \mathrm{dl}$. El grado de anemia se clasificó en leve $(<11,0 \mathrm{~g} / \mathrm{dl}$ en niños menores de 4 años y 11 meses y $11,5 \mathrm{~g} / \mathrm{dl}$ en niños de cinco años), moderado $(<10 \mathrm{~g} / \mathrm{dl})$ y grave $(<7 \mathrm{~g} / \mathrm{dl})$; todos los datos se corrigieron por altura sobre el nivel del mar $(6,34)$.

Ferritina sérica: se cuantificó utilizando la metodología de inmunoensayo enzimático de micropartículas. Para el análisis, los datos se clasificaron en los rangos de $>12 \mathrm{ug} / \mathrm{L}$ como normalidad y $<12$ ug/L como deficiencia, según parámetros del Grupo Consultivo Internacional de Anemia, INACG (35-37). 
Retinol plasmático: para la cuantificación se utilizó una adaptación del método espectofotométrico de Bessey y colaboradores (38); cuando los resultados fueron $<25 \mathrm{mg} / \mathrm{dL}$ se repitieron por cromatografía líquida de alta resolución. Para la clasificación de las concentraciones de retinol plasmático se tomaron los siguientes rangos: valor normal, > 30mg/dL, riesgo de deficiencia, 20-29,9mg/ $\mathrm{dL}$ y concentraciones deficientes, $<20 \mathrm{mg} / \mathrm{Dl}$, con base en la referencia de la OMS (39-44).

Muestras de coprológico: se utilizó la técnica de concentración formol-éter y el recuento de huevos se realizó mediante el método de concentración de Ritchie-Frick modificado $(45,46)$.

\section{Valoración antropométrica}

La toma de las medidas antropométricas la realizaron nutricionistas dietistas previamente entrenadas y estandarizadas. Para tomar el peso se utilizó una balanza digital con batería solar marca Tanita, sensibilidad de $200 \mathrm{~g}$ y capacidad de $150 \mathrm{~kg}$. La estatura se midió con un tallímetro en madera con pieza movible y medición en centímetros y milímetros con una exactitud de $1 \mathrm{~mm}$.

La clasificación del estado nutricional de los preescolares se hizo en puntaje $Z$ según los indicadores peso/talla, talla/edad y peso/edad recomendados por la OMS. Los puntos de corte para la clasificación nutricional también siguen los valores recomendados por la OMS y los utilizados internacionalmente para indicar desnutrición $(<-2$ DS según indicadores de peso/talla, peso/edad y talla/edad) y exceso de peso (> 2,0 DS según indicadores de peso/talla y peso/edad).

Además, se incluyó un rango de riesgo de desnutrición entre -1 DS y -2 DS para los indicadores de peso/talla, peso/edad y talla/edad, descrito en algunos estudios que lo mencionan como punto de corte avalado igualmente por la OMS y en otros que ratifican su utilización, especialmente en vigilancia nutricional (47-54). Este rango de riesgo permite ampliar el espectro de probabilidad para demostrar la existencia o no de asociación entre desnutrición y deficiencia de micronutrientes en esta población; en cualquier evaluación del estado nutricional, la selección de un punto de corte puede llevar a que se diagnos- tiquen como desnutridos a niños que pueden ser normales o a la inversa; la selección depende del interés particular con el que se realiza el estudio.

Teniendo en cuenta estos criterios, la clasificación nutricional se hizo de la siguiente manera: para el indicador peso/edad y talla/edad se clasificó en normal (-1,0 a +1,9 DS), riesgo de bajo peso (-2,0 a $-1,1 \mathrm{DS})$, bajo peso (<-2,0 DS) y exceso de peso (>2,0 DS); el indicador talla/edad se clasificó como normal (>-1,0 DS), riesgo (-2,0 a -1,1 DS) y retardo en el crecimiento ( $<-2,0 \mathrm{DS})$.

Los valores de referencia de peso y estatura para hacer la clasificación nutricional por los indicadores estatura para la edad, peso para la edad y peso para la talla corresponden a las curvas de referencia y crecimiento estándar desarrollados por el National Center For Health Statistic (NCHS) de los Estados Unidos de América, que han sido adoptados como patrón internacional (49).

\section{Encuesta sobre factores asociados a deficiencia de hierro y vitamina A}

Los datos de identificación y los factores de riesgo asociados a anemia nutricional, deficiencia de hierro y deficiencia de vitamina $A$ se determinaron mediante encuesta a la madre del niño o a la persona responsable de su alimentación. La elección de los factores de riesgo incluidos en la encuesta se realizó teniendo en cuenta la literatura científica $(10,11,13,15,17,19,20,24,25,28)$ e información existente sobre la situación nutricional de la población de Cundinamarca y el municipio de Funza.

Las variables evaluadas estaban relacionadas con características socioeconómicas, demográficas, de medio ambiente, clínicas y nutricionales: estrato socioeconómico, número de niños menores de cinco años por familia, edad de la madre, escolaridad del padre y la madre, ocupación de la madre, forma de tenencia de la vivienda, tipo de vivienda, proporción de personas que aportan económicamente, salarios mínimos recibidos per cápita, personas por dormitorio, condiciones de salud del niño (el niño se enfermó en el último mes o no), parasitismo intestinal, duración de la lactancia materna exclusiva, consumo de suplementos, asistencia a charlas de alimentación 
y nutrición, participación en programas de alimentación y nutrición del municipio.

\section{Evaluación de la frecuencia de consumo de alimentos fuente de hierro $y$ vitamina $A$}

Se utilizó una encuesta dietética simplificada mediante el interrogatorio de la frecuencia de consumo de alimentos fuente de hierro y vitamina A (55), tomando en cuenta una frecuencia de consumo diaria, semanal y mensual. La encuesta de frecuencia de consumo de alimentos se elaboró con base en los alimentos ricos en los micronutrientes de consumo usual de esta comunidad, basándose en la observación previa de los productos ofrecidos en los sitios de mercado del municipio. También se tuvo en cuenta un contenido alto de hierro y vitamina A determinado por la tabla de composición de alimentos colombiana (56). Se interrogó igualmente sobre la frecuencia de consumo de alimentos fortificados y enriquecidos. El cuestionario de frecuencia fue contestado por la madre del niño o la persona responsable de su alimentación.

\section{Análisis estadístico}

La base de datos y el análisis estadístico se realizó en el sistema EPI-INFO versión 6.04d. Se establecieron distribuciones de frecuencia y el comportamiento conjunto de dos variables categóricas se representó con tablas de contingencia, la fuerza de la asociación entre las variables categóricas se describió por razón de prevalencias. Para decidir acerca de la dependencia entre las variables categóricas se aplicó la prueba ji cuadrado de independencia; cuando algunas casillas de la tabla tenían frecuencias bajas esta prueba se sustituyó por la prueba de Fisher-Irwing.

Para decidir acerca de la significación de las diferencias entre las medias de las variables continuas se aplicó la prueba $\mathrm{T}$ para la comparación de medias de dos poblaciones independientes teniendo en cuenta si las varianzas eran iguales o no; para ello se aplicó previamente la prueba de Levene. Estas pruebas estadísticas se complementaron en el análisis con intervalos de confianza (IC) del 95\% para la razón de prevalencias.

\section{Consideraciones éticas}

Se llevaron a cabo diferentes reuniones de presentación de la investigación. Los padres de los preescolares autorizaron la participación de sus hijos en el estudio mediante su firma en el consentimiento informado. En el consentimiento informado se incluyeron los riesgos del niño al participar en este estudio, especificando que éstos se derivan de la toma de la muestra de sangre por venopunción en cantidad de $5 \mathrm{~mL}$ (alguna probabilidad de hinchazón leve y mareo), según lo dispuesto en la Resolución No. 008430 de 1993 del Ministerio de Salud y en la Ley 84 de 1989.

Los resultados se presentaron en las instituciones municipales que tienen injerencia en la toma de decisiones en salud y a las familias se les entregó un plegable con los resultados de antropometría, hemoglobina y recomendaciones generales para una adecuada alimentación. Los resultados de ferritina, retinol y parasitismo se enviaron posteriormente a los colegios para ser entregados a los padres de familia con una recomendación general de asistir a consulta médica en caso de alguna alteración. Este proyecto recibió el aval del Comité de Ética del Instituto Nacional de Salud.

\section{Resultados}

\section{Características demográficas}

De un total de 286 niños se encontró una distribución por género homogénea, $51,4 \%$ femenino y $48,6 \%$ masculino; el índice de masculinidad fue de $94,6 \%$; el $23,4 \%$ de la población asiste a instituciones oficiales, y de éste, el 1,7\% acude a instituciones educativas oficiales rurales, el $52,1 \%$ a instituciones privadas (jardín o colegio) y el $24,5 \%$ a Hogares Comunitarios del ICBF.

\section{Variables bioquímicas}

Los resultados de las variables bioquímicas evaluadas se presentan en el cuadro 1. La prevalencia de anemia fue de 40,8\%; el $32 \%$ de la población presentó anemia leve, el 8,4\% anemia moderada y el $0,4 \%$ anemia grave. La mayor prevalencia se observó en los Hogares Comunitarios del ICBF, seguidos por los colegios oficiales y privados con prevalencias similares. 
El 5,2\% de la población presentó deficiencia de hierro, con mayor prevalencia en los preescolares de colegios privados, seguidos por los niños y niñas de Hogares Comunitarios del ICBF; en los colegios oficiales no se encontró deficiencia. La deficiencia de hierro por género fue similar.

El 4,6\% de los preescolares presentó deficiencia de vitamina $\mathrm{A}$ y el $36 \%$, riesgo de adquirirla. Al hacer la distinción por género se evidenciaron deficiencias similares entre niños y niñas y una prevalencia de riesgo mayor en los niños. Por institución, la mayor prevalencia de deficiencia de vitamina $A$ se observó en los niños de los Hogares Comunitarios del ICBF, seguidos por los niños de colegios privados; en colegios oficiales no se encontró deficiencia. Según el tipo de institución, el riesgo de deficiencia de vitamina $A$ fue mayor en los colegios oficiales. En los preescolares de Hogares Comunitarios del ICBF y de colegios privados el riesgo de deficiencia de

Cuadro 1. Estado nutricional evaluado por antropometría y prevalencia de déficit de hierro, anemia, deficiencia de hierro y parasitismo intestinal en la población de estudio.

\begin{tabular}{|c|c|c|c|c|c|c|}
\hline \multirow[t]{3}{*}{ Variables } & \multirow{2}{*}{$\begin{array}{c}\text { Prevalencia en el } \\
\text { total de la población } \\
\text { evaluada }\end{array}$} & \multirow{3}{*}{$\begin{array}{l}\text { Prevalencia } \\
\text { en niños }\end{array}$} & \multirow{3}{*}{$\begin{array}{l}\text { Prevalencia } \\
\text { en niñas }\end{array}$} & \multicolumn{3}{|c|}{ Prevalencia por tipo de institución \% } \\
\hline & & & & \multirow{2}{*}{$\begin{array}{l}\text { Institución } \\
\text { educativa } \\
\text { oficial }\end{array}$} & \multirow{2}{*}{$\begin{array}{c}\text { Hogares } \\
\text { Comunitarios } \\
\text { ICBF }\end{array}$} & \multirow{2}{*}{$\begin{array}{c}\text { Institución } \\
\text { educativa } \\
\text { privada }\end{array}$} \\
\hline & & & & & & \\
\hline \multicolumn{7}{|l|}{$\begin{array}{l}\text { Antropométricas } \\
\mathrm{N}=267 \\
\text { Indicador talla/edad }\end{array}$} \\
\hline Retardo en talla & 9,7 & 11,5 & 8,1 & 9,5 & 13,2 & 8,1 \\
\hline \multicolumn{7}{|l|}{ Indicador peso/talla } \\
\hline Déficit de peso & 1,1 & 1,6 & 0,7 & 1.6 & 1,5 & 0,7 \\
\hline Riesgo & 11,2 & 14,5 & 8,1 & 7,9 & 11,8 & 12,5 \\
\hline \multicolumn{6}{|l|}{ Indicador peso/edad } & \\
\hline Bajo peso para la edad & 3,4 & 5,3 & 1,5 & 3,2 & 4,4 & 2,9 \\
\hline Riesgo & 28,1 & 30,5 & 25,7 & 34,9 & 27,9 & 25,0 \\
\hline Exceso de peso & 0,4 & & & & & \\
\hline \multicolumn{7}{|l|}{$\begin{array}{l}\text { Bioquímicas y } \\
\text { parasitismo intestinal } \\
\text { Hemoglobina } \\
\mathrm{N}=250\end{array}$} \\
\hline Anemia & 40,8 & 39,2 & 42,5 & 37,3 & 54,1 & 35,9 \\
\hline Anemia leve & 32 & & & 33,9 & 38,1 & 28,1 \\
\hline Anemia moderada & 8,4 & & & $1,7^{*}$ & 15,9 & 7,8 \\
\hline Anemia grave & 0,4 & & & & & \\
\hline \multicolumn{7}{|l|}{$\begin{array}{l}\text { Ferritina } \\
\mathrm{N}=230\end{array}$} \\
\hline Deficiencia de hierro & 5,2 & 5,4 & 5,0 & Sin deficiencia & 5,3 & 7,6 \\
\hline \multicolumn{7}{|l|}{$\begin{array}{l}\text { Retinol plasmático } \\
\mathrm{N}=175\end{array}$} \\
\hline Deficiencia & 4,6 & 4,8 & 4,4 & Sin deficiencia & 6,7 & 5,6 \\
\hline Riesgo de deficiencia & 36 & 40,5 & 31,9 & 31,7 & 37,8 & 37,1 \\
\hline \multicolumn{7}{|l|}{$\begin{array}{l}\text { Parasitismo intestinal } \\
N=198\end{array}$} \\
\hline Parasitismo & 51 & & & & & \\
\hline Patógenos & 6,9 & & & & & \\
\hline No patógenos & 79,2 & & & & & \\
\hline Patógenos y no patógenos & 13,9 & & & & & \\
\hline
\end{tabular}

* Anemia moderada y grave 
vitamina A presentó una prevalencia similar (cuadro 1).

\section{Parasitismo intestinal}

La prevalencia de parásitos intestinales se describe en el cuadro 1 . Se encontró principalmente Blastocystis hominis (34,8\%), Entamoeba coli $(21,7 \%)$ y Giardia duodenalis $(8,1 \%)$. La prevalencia de Ascaris lumbricoides y Trichuris trichuria fue del 0,5\%, de Entamoeba histolytica, $1,5 \%$ y de Cryptosporidium sp, $48,5 \%$.

\section{Valoración antropométrica}

Los resultados de la evaluación antropométrica se muestran en el cuadro 1 . El retardo en talla se presentó en el 9,7\% de la población, el déficit de peso para la talla en el 1,1\% y la deficiencia de peso para la edad en el 3,4\% de la población. Las mayores prevalencias de retardo en talla, bajo peso para la talla, bajo peso para la edad y riesgo para las mismas se registraron en el género masculino.
Según el tipo de institución, los preescolares de colegios oficiales y de los Hogares Comunitarios de ICBF presentaron un déficit de peso para la talla similar y mayor a la presentada en los colegios privados. El porcentaje de niños con retardo en talla fue mayor en los Hogares Comunitarios del ICBF, seguido por el de los preescolares de colegios oficiales y colegios privados. El bajo peso para la edad fue mayor en preescolares de Hogares Comunitarios, seguidos por los colegios oficiales y privados.

\section{Frecuencia de consumo de alimentos fuente de hierro y vitamina A}

La frecuencia de consumo de alimentos fuente de vitamina A y hierro se detalla en el cuadro 2. Respecto a la frecuencia de consumo de alimentos fuente de vitamina $A$, más del $70 \%$ de los preescolares refirió consumo de huevo, frutas, verduras y lácteos y la frecuencia de consumo fue principalmente en la categoría de diaria. El

Cuadro 2. Frecuencia de consumo de alimentos fuente de hierro y vitamina $A$ en preescolares del municipio de Funza, Cundinamarca, Colombia.

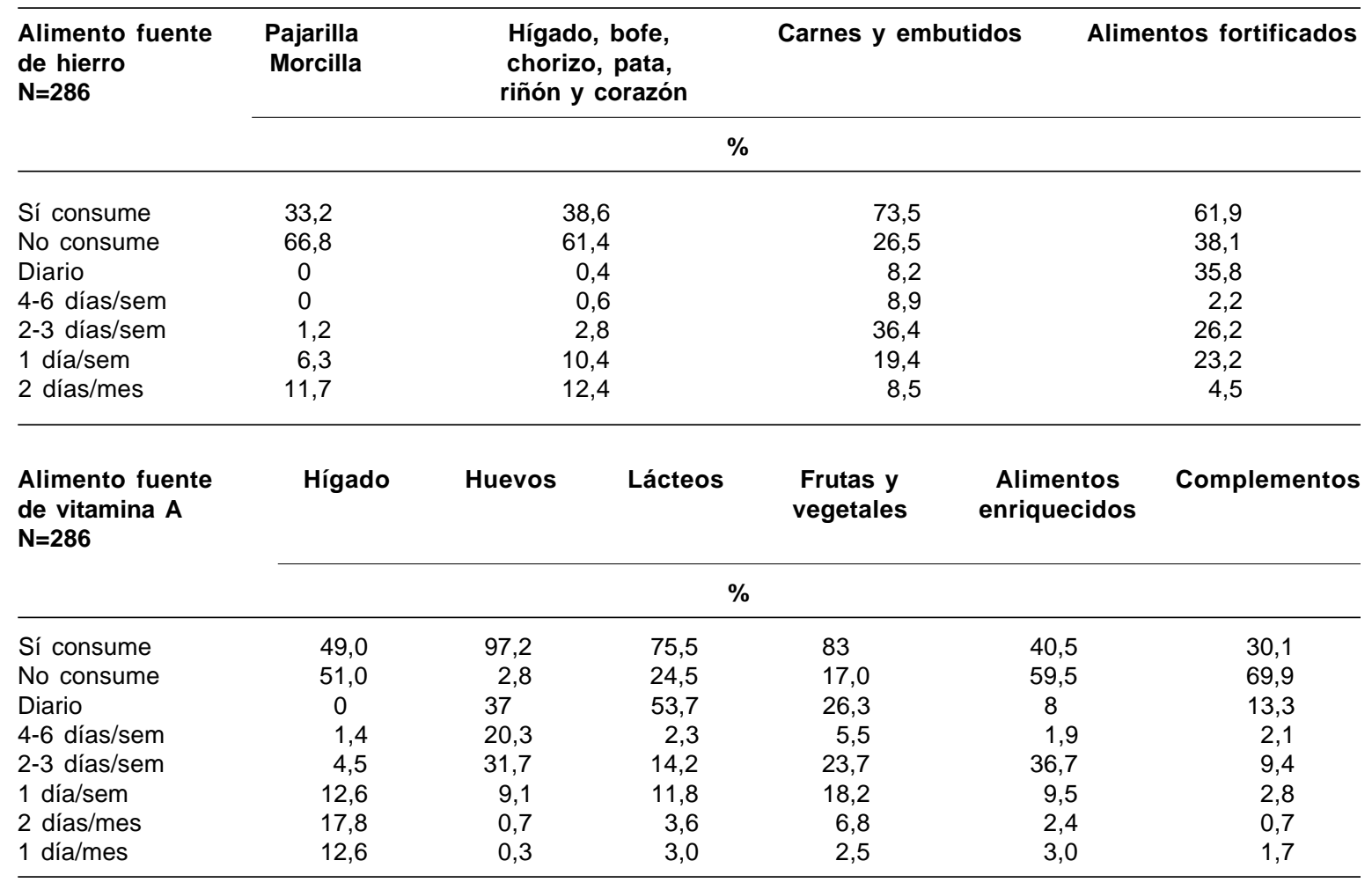


consumo de fuentes de vitamina A informado fue menor para complementos, alimentos enriquecidos e hígado. En cuanto a la frecuencia de consumo de alimentos fuente de hierro, los alimentos que más se reportaron pertenecían a la categoría de carnes y embutidos y alimentos fortificados, con un porcentaje de consumo en la población de más del $60 \%$; la frecuencia de consumo de alimentos fortificados se reportó principalmente como diaria y la de carnes y embutidos, dos a tres días por semana. Los alimentos fuente de hierro que menos se reportaron corresponden a la categoría de vísceras.

Frecuencia de factores de riesgo para deficiencia de hierro y vitamina $A$ en la población y asociación estadística con las deficiencias de micronutrientes

Los resultados de la encuesta sobre las variables evaluadas relacionadas con características socioeconómicas, demográficas, de medio ambiente, clínicas y algunas relacionadas con alimentación de los niños se describen en los cuadros 3 y 4 . Los predictores de riesgo que se determinaron para compararlos con la prevalencia de anemia, deficiencia de hierro y de vitamina $A$ se describen en los cuadros 5, 6 y 7 .

En los resultados de la encuesta resalta la alta frecuencia de algunos de los factores de riesgo reportados para deficiencia de hierro y vitamina A: la totalidad de la población pertenece a un estrato socioeconómico bajo; la forma de tenencia de la vivienda que predomina es en arriendo, con un gran porcentaje de la población que vive en inquilinato; las condiciones de la vivienda y los servicios básicos son aceptables en el sector urbano pero deficientes en la zona rural; aunque la mayoría de las familias cuentan con uno o dos integrantes que aportan a los gastos del hogar, el ingreso familiar es bajo, con un promedio de 2,3 salarios mínimos vigentes, pero el más frecuente es de sólo un salario mínimo (cuadro 3).

En el estudio, la tercera parte de las madres refirió que el niño presentó algún tipo de enfermedad infecciosa en el último mes, siendo la más prevalente la infección respiratoria; más del $60 \%$ realiza prácticas inadecuadas de alimentación durante la enfermedad. También se encontró que la mayoría de las madres lactó a sus hijos, pero el promedio de duración de la lactancia exclusiva fue de 4,1 meses y el promedio del destete fue de 15,9 meses (cuadro 4).

Estadísticamente, las variables que mostraron asociación significativa fueron la presencia de anemia y la variable tipo de vivienda inquilinato ( $p=0,002$; RR: 1,80; IC: 1,01 a 1,81), y no ser beneficiario de algún programa nutricional ( $p=0,04$; RR: 1,35 ; IC: 1,01 a 1,81); la deficiencia de vitamina $A$ mostró asociación con la variable de morbilidad sentida en el último mes ( $p=0,04$; RR: 1,52; IC: 1,00 a 2,3).Los demás factores de riesgo no mostraron asociación estadísticamente significativa con las concentraciones de hemoglobina, ferritina y retinol sérico $(p>0,05)$ (cuadros $5,6$ y 7$)$.

\section{Discusión}

En el estudio se encontró alta prevalencia de anemia, que en la población preescolar asistente a Hogares Comunitarios afectó a más del $50 \%$ de los niños. Al comparar la prevalencia de anemia en la población preescolar de Funza con algunos datos del nivel nacional se observó que es mayor a la reportada para niños menores de cinco años en 1995 y en el 2005 ( $23 \%$ y 33,2\%, respectivamente); igualmente, es mayor a la descrita para la región central en estos mismos años $(22,7 \%$ en 1995 y $24,3 \%$ en 2005) $(9,32)$.

El valor de ferritina indicó una prevalencia de deficiencia de hierro de 5,2\%, menor a la encontrada para menores de cinco años en el país y en la región central en 1995 y 2005 (en 1995 el $18 \%$ para el país y para la región central, en el 2005 , el $10,4 \%$ para la región central y $12 \%$ para el total del país) $(9,32)$; por otro lado, resultó ser inferior a la prevalencia de anemia hallada en estos preescolares. Estos datos sugieren que probablemente la deficiencia de hierro no es la única causa de anemia en esta población. Posiblemente también se asocie a infección y a deficiencia de ácido fólico y vitamina $B_{12}$, consideradas de escasa prevalencia en los diferentes grupos de población del mundo, pero que por el bajo consumo de alimentos de origen animal y de vegetales verde oscuro se empieza a evidenciar como problema nutricional en distintas poblaciones 
Cuadro 3. Características socioeconómicas, demográficas, de medio ambiente y clínicas de la población estudio. Resultados de la encuesta, preescolares del municipio de Funza, Cundinamarca, Colombia.

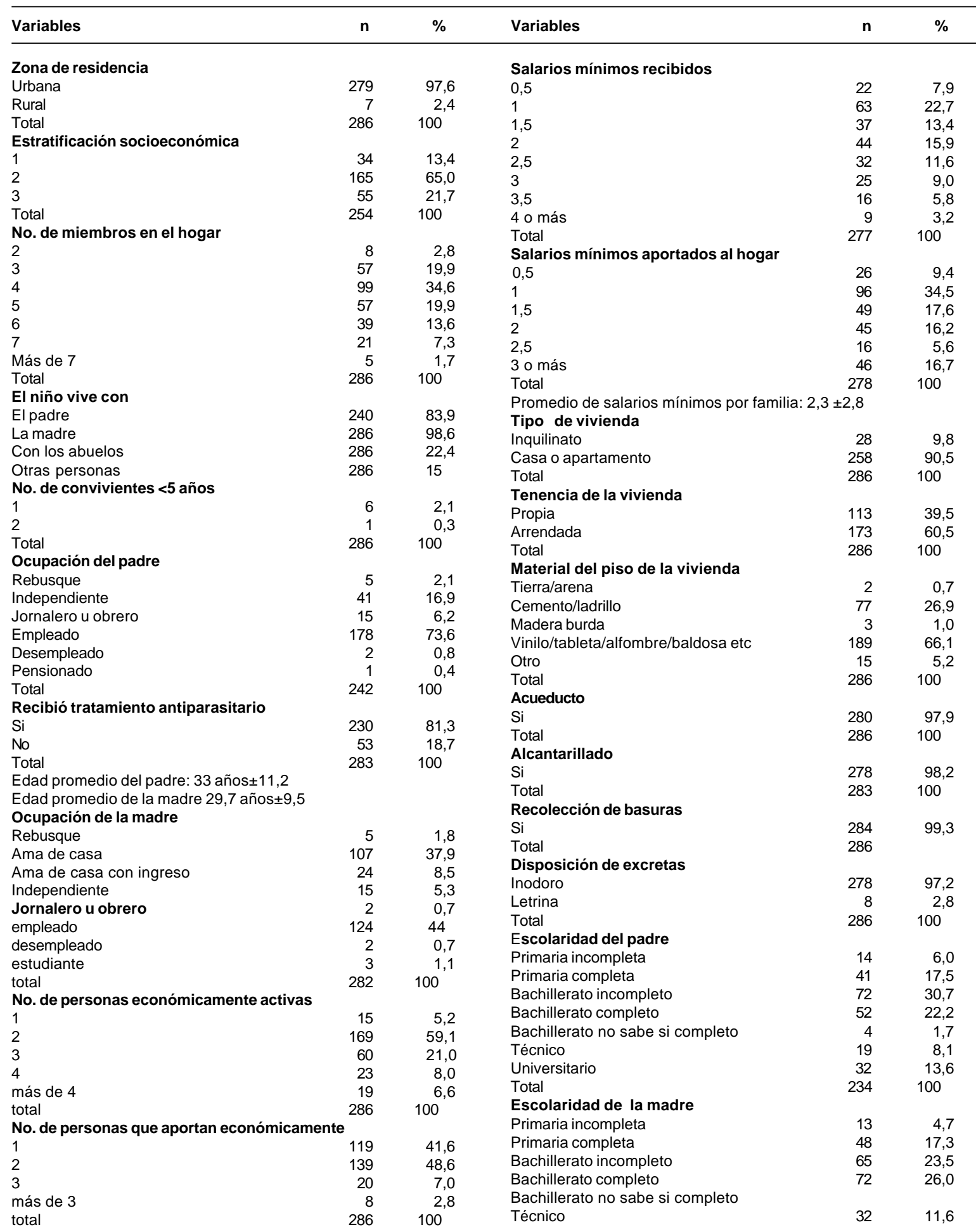


Cuadro 3 (continuación). Características socioeconómicas, demográficas, de medio ambiente y clínicas de la población estudio. Resultados de la encuesta, preescolares del municipio de Funza, Cundinamarca, Colombia.

\begin{tabular}{|c|c|c|c|c|c|}
\hline Variables & $\mathbf{n}$ & $\%$ & Variables & $\mathbf{n}$ & $\%$ \\
\hline Universitario & 47 & 17,0 & Diarrea & & \\
\hline Total & 277 & 100 & No se enfermó & 74 & 90,2 \\
\hline El niño se enfermó en el último mes & & & Hoy & 1 & 1,2 \\
\hline Sí & 82 & 28,7 & Semana & 1 & 1,2 \\
\hline No & 97 & 33,9 & Quince Días & 1 & 1,2 \\
\hline No respondió & 107 & 37,4 & Mes & 4 & 4,9 \\
\hline Total & 286 & 100 & No sabe & 1 & 1,2 \\
\hline Infección respiratoria & & & Total & 82 & 100 \\
\hline No se enfermó & 12 & 14,6 & Otras & & \\
\hline Hoy & 17 & 20,7 & No se enfermó & 72 & 87,8 \\
\hline Semana & 5 & 6,1 & Hoy & 1 & 1,2 \\
\hline Quince días & 9 & 11,0 & Semana & 1 & 1,2 \\
\hline Mes & 38 & 14,6 & Quince Días & 1 & 1,2 \\
\hline No sabe & 1 & 1,2 & Mes & 6 & 7,3 \\
\hline Total & 82 & 100 & No sabe & 1 & 1,2 \\
\hline Parasitosis & & & Total & 82 & 100 \\
\hline No se enfermó & 81 & 98,8 & Hace cuánto tiempo & & \\
\hline No sabe & 1 & 1,2 & Menos o igual a 1 mes & 24 & 10,4 \\
\hline Total & 82 & 100 & Más de 1 mes & 206 & 89,6 \\
\hline & & & Total & 230 & 100 \\
\hline
\end{tabular}

$(34,57)$. Sin embargo, es importante tener en cuenta que en este estudio la prevalencia de deficiencia de hierro estimada por ferritina podría estar subvalorada porque no se realizó análisis bioquímico de proteína $\mathrm{C}$ reactiva. La proteína $\mathrm{C}$ reactiva es un reactante de la fase aguda que se encuentra en concentraciones bajas en el suero de personas sanas. Durante la respuesta a la fase aguda de una reacción inflamatoria, los niveles de reacción en cadena de la polimerasa (PCR) se elevan, convirtiéndolos en un indicador temprano de infección; por esta razón este indicador permite distinguir las anemias ferroprivas de las secundarias a infección (58).

Aunque en esta investigación no se realizó un recordatorio de 24 horas para conocer con mayor exactitud el consumo de alimentos de la población, los resultados de la frecuencia de consumo de alimentos fuente de hierro y vitamina $A$ sugieren la probabilidad de que exista deficiencia de $B_{12} y$ ácido fólico, teniendo en cuenta la baja frecuencia de consumo de algunos alimentos de origen animal que son fuente de hierro y factor de riesgo importante de anemia ferropénica $(13,59)$, pero a la vez son fuente de ácido fólico y $\mathrm{B}_{12}$, tales como, vísceras, hígado y lácteos. Sería necesario aclarar la hipótesis de probable deficiencia de vitamina $\mathrm{B}_{12} \mathrm{y}$ ácido fólico mediante análisis bioquímico, evaluación del consumo de alimentos fuente de vitamina $B_{12}$ y ácido fólico y factores de riesgo asociados a la deficiencia de estos otros dos micronutrientes $(34,57)$.

La deficiencia de vitamina $A$ en los preescolares no fue tan prevalente, pues su valor resultó inferior al reportado en el país para los años 1995 y 2005, en los que las prevalencias fueron de 14,2\% (catalogado por la OMS como un problema moderado de salud pública) y $5,9 \%$, respectivamente $(9,32)$. Al comparar la prevalencia hallada con los datos de la región central se observó un valor inferior al reportado en la región para 1995 (11\%), pero mayor al que se determinó en el 2005 (2,3\% según ENSIN 2005) $(9,32)$.

Los datos de deficiencia de vitamina $A$ en preescolares presentan grandes variaciones según el país. Al comparar los datos de Funza con datos en niños costarricenses y ecuatorianos, la deficiencia en Funza resultó ser menor; para Costa Rica la deficiencia equivale al $8,8 \%$ de la población y en niños ecuatorianos llega a ser del $18 \%$ de los preescolares. Estas diferencias en las prevalencias probablemente reflejan las características particulares de cada país, que hacen que la probabilidad de presentación de la deficiencia nutricional también difiera. Estas discrepancias se pueden relacionar entre otros aspectos con la condición socioeconómica de 
Cuadro 4. Variables relacionadas con la práctica de lactancia materna, la alimentación complementaria, el uso de suplementos, la preparación de alimentos y el apoyo alimentario de la población de estudio. Resultados de la encuesta, preescolares del municipio de Funza, Cundinamarca, Colombia.

\begin{tabular}{|c|c|c|c|c|c|}
\hline Variable & $\mathbf{n}$ & $\%$ & Variable & $\mathbf{n}$ & $\%$ \\
\hline Lactancia materna & & & Cada cuánto le ofrece emulsión de Scott & & \\
\hline Sí & 272 & 95,4 & Diario & 2 & 3,0 \\
\hline No & 13 & 4,6 & 2-3 días/semana & 3 & 4,5 \\
\hline Total & 285 & 100 & 4-6 días/semana & 3 & 4,5 \\
\hline Duración de la lactancia exclusiva & & & 1 día/semana & 2 & 3,0 \\
\hline$<4$ meses & 62 & 22,8 & $1 \mathrm{día} / \mathrm{mes}$ & 56 & 84,8 \\
\hline 4- 6 meses & & & Total & 66 & 100 \\
\hline$>6$ meses & 39 & 14,3 & Daya mineral & & \\
\hline Total & 272 & 100 & 1 día/mes & 4 & 100 \\
\hline Promedio duración lactancia exclusiva: & & & Total & 4 & 100 \\
\hline 4,1 meses $\pm 3,5$ & & & Sulfato ferroso & & \\
\hline Edad del destete & & & Diario & 2 & 28,6 \\
\hline$>24$ meses & 55 & 20,2 & 1 día/mes & 5 & 71,4 \\
\hline$>18-\leq 24$ meses & 29 & 10,7 & Total & 7 & 100 \\
\hline$>12-\leq 8$ meses & 28 & 10,3 & Hace cuánto comenzó a tomarlo & & \\
\hline$>6-\leq 12$ meses & 56 & 20,6 & Emulsión de Scott & & \\
\hline$\leq 6$ meses & 104 & 38,2 & Menos de 6 meses & 35 & 53,0 \\
\hline Total & 272 & 100 & 6-12 meses & 9 & 13,6 \\
\hline Leche de fórmula & & & Más de 12 meses & 22 & 33,3 \\
\hline Sí & 211 & 75,1 & Total & $\overline{66}$ & 100 \\
\hline No & 70 & 24,9 & Daya mineral & & \\
\hline Total & 281 & 100 & Menos de 6 meses & 3 & 75,0 \\
\hline Edad de introducción de leche de fórmula & & & Más de 12 meses & 1 & 25,0 \\
\hline$>6$ meses & 150 & 23,7 & Total & 4 & 100 \\
\hline$\leq 6$ meses & 161 & 76,3 & Sulfato ferroso & & \\
\hline Total & 211 & 100 & Menos de 6 meses & 7 & 100 \\
\hline Leche de vaca & & & Más de 6 meses & 9 & 13,6 \\
\hline Sí & 276 & 97,9 & Menos de 12 meses & 22 & 33,3 \\
\hline No sabe & 6 & 2,1 & Más de 12 meses & 66 & 100 \\
\hline Total & 282 & 100 & Es beneficiario de algún programa nutricional & & \\
\hline Edad de introducción de la leche de vaca & & & Sí & 104 & 36,4 \\
\hline$\leq 12$ meses & 165 & 59,8 & No & 182 & 63,6 \\
\hline$<6$ meses & 47 & 17,0 & Total & 286 & 100 \\
\hline$\leq 6 \leq 12$ meses & 64 & 23,2 & Tipo de programa & & \\
\hline Total & 276 & 100 & Materno infantil & 1 & 1 \\
\hline Inicio de la alimentación complementaria & & & Recuperación nutricional & 3 & 2,9 \\
\hline$>6$ meses & 87 & 30,4 & Desayuno escolar & 33 & 31,7 \\
\hline$\leq 6$ meses & 199 & 69,6 & Almuerzo escolar & 15 & 14,4 \\
\hline Total & 286 & 100 & Hogar comunitario & 64 & 61,5 \\
\hline Consumió algún suplemento & & & Quién prepara los alimentos & & \\
\hline Sí & 111 & 39,4 & Papá & 1 & 3,8 \\
\hline No & 171 & 60,6 & Mamá & 235 & 82,2 \\
\hline Total & 282 & 100 & Abuelo & 1 & 0,3 \\
\hline Emulsión de Scott & & & Abuela & 35 & 12,2 \\
\hline Sí & 80 & 72,1 & Otra Persona & 6 & 2,9 \\
\hline No & & & Total & 286 & 100 \\
\hline Total & 111 & 100 & Quién decide respecto al niño & & \\
\hline Daya mineral & & & Papá & 57 & 19,9 \\
\hline Sí & 4 & 3,6 & Mamá & 205 & 71,7 \\
\hline No & 107 & 96,4 & Abuelo & 1 & 0,3 \\
\hline Total & 111 & 100 & Abuela & 22 & 7,7 \\
\hline Sulfato ferroso & & & Otra Persona & $\overline{1}$ & 0,3 \\
\hline Sí & 7 & 6,31 & Total & 286 & 100 \\
\hline No & 104 & 93,7 & & & \\
\hline \multirow{2}{*}{\multicolumn{6}{|c|}{ Daya mineral }} \\
\hline & & & & & \\
\hline Menos de 6 meses & 3 & 75,0 & & & \\
\hline Más de 12 meses & 1 & 25,0 & & & \\
\hline Total & 4 & 100 & & & \\
\hline
\end{tabular}

cada grupo poblacional o con las diferencias en el perfil de morbilidad $(57,60)$.

La población que se encontró en la categoría de riesgo para deficiencia de vitamina A fue considerable. Esta situación podría aumentar la población con deficiencia si los factores relacionados con el estado nutricional del micronutriente se modifican de forma desfavorable. Al igual que con la deficiencia de vitamina $A$, la población preescolar en riesgo según el país es diferente. Un estudio en preescolares del Ecuador señaló prevalencias de riesgo muy por encima al que se halló en el municipio de Funza, alcanzando valores 
Cuadro 5. Predictores de riesgo usados para buscar asociación estadística con anemia medida por hemoglobina, resultados estadísticos.

\begin{tabular}{|c|c|c|c|c|c|}
\hline \multicolumn{6}{|c|}{ Anemia } \\
\hline Variables & Predictor de riesgo & Valor de $p$ & $\begin{array}{c}\text { Razón de } \\
\text { prevalencias }\end{array}$ & $\begin{array}{c}\text { Intervalo de } \\
\text { confianza } 95 \%\end{array}$ & Ji cuadrado \\
\hline \multicolumn{6}{|c|}{ Sociodemográficas y de salud } \\
\hline Estrato socioeconómico & 102 & 0,324 & & & 2,194 \\
\hline No. de niños menores de 5 años & 2 o más & 0,586 & & & 0,30 \\
\hline Edad de la madre & $<250>40$ & 0,105 & 1.31 & $0,96-1,79$ & 2,62 \\
\hline Escolaridad de la madre & primaria & 0,564 & & & 2,964 \\
\hline Escolaridad del padre & primaria & 0,174 & & & 7,693 \\
\hline Ocupación de la madre & ama de casa & 0,608 & 0,91 & $0,62-1,32$ & 0,26 \\
\hline Tenencia de la vivienda & arrendada & 0,283 & 1,18 & $0,88-1,58$ & 1,15 \\
\hline Tipo de vivienda & inquilinato & 0,002 & 1,80 & $1,33-2,45$ & 9,12 \\
\hline Condiciones de salud del niño & enfermedad en el mes anterior & 0,432 & 1,16 & $0,80-1,70$ & 0,62 \\
\hline \multirow[t]{2}{*}{ Desparasitación } & $>1$ mes & 0,550 & 0,84 & $0,45-1,55$ & 0,36 \\
\hline & De alimentación & & & & \\
\hline Duración de la lactancia exclusiva & $<60>6$ meses & 0,134 & 1,30 & $0,91-1,86$ & 2,24 \\
\hline $\begin{array}{l}\text { Recibió charlas de alimentación } \\
\text { Es beneficiario de algún programa }\end{array}$ & $\begin{array}{l}\text { no recibió charlas de alimentación } \\
\text { no es beneficiario de algún programa }\end{array}$ & 0,232 & 0,69 & $0,37-1,30$ & 1,42 \\
\hline de alimentación y nutrición & de alimentación y nutrición & 0.044 & 1,35 & $1,01-1,81$ & 4,06 \\
\hline Pajarilla, morcilla. & consumió hace más de un mes & 0.699 & 1,06 & $0,79-1,42$ & 0,15 \\
\hline $\begin{array}{l}\text { Bofe, chorizo, pata, riñón, corazón, } \\
\text { hígado. }\end{array}$ & consumió hace más de una semana & 0,615 & 1,08 & $0,80-1,46$ & 0,25 \\
\hline Carnes, embutidos y sardinas. & consumió hace más de un día & 0,507 & 0,91 & $0,67-1,22$ & 0,44 \\
\hline \multirow[t]{2}{*}{ Alimentos fortificados. } & consumió hace más de un día & 0,217 & 0,82 & $0,60-1,11$ & 1,2 \\
\hline & Antropométricas & & & & \\
\hline Talla para la edad, & retraso en el crecimiento $<2$ DS & 0,688 & & $0,39-1,87$ & 0,16 \\
\hline Peso para la talla & bajo peso para la talla $<2 D S$ & 0,777 & & $0,07-7,72$ & 0,08 \\
\hline Peso para la edad & desnutrición global & 0,846 & & $0,31-4,13$ & 0,04 \\
\hline
\end{tabular}

del $60 \%$ de la población, mientras que en preescolares de Costa Rica es cercana al 30\% $(57,60)$. En uno de estos estudios se sugiere que es posible reducir la mortalidad infantil si se suplementa a la población que se encuentra en el rango de riesgo (60).

En este estudio se presentan diversas limitaciones que deben considerarse al interpretar los datos bioquímicos: primero, la muestra que se calculó tiene un error de estimación que no corresponde al $5 \%$, considerado como el mínimo ideal, debido a que fue necesario ajustarla de acuerdo a la disponibilidad financiera y de recurso humano; segundo, resultó ser inferior a la estimada para la evaluación bioquímica porque la cantidad de sangre que se pudo extraer en algunos niños fue insuficiente para cuantificar los tres indicadores bioquímicos; por esta razón, el estudio no puede concluir sobre la situación de la vitamina A o el hierro en todo el municipio. Los resultados,por consiguiente, reflejan la prevalencia de deficiencia de vitamina $A$ y hierro en un grupo de población preescolar que asiste a instituciones públicas y privadas de educación y a Hogares Comunitarios de Bienestar Familiar; además, como se mencionó anteriormente, no se evaluó la PCR, situación que puede subvalorar los datos reales de deficiencia de hierro.

En la evaluación antropométrica se encontraron preescolares de las tres instituciones con déficit de peso para la talla o para la edad, retardo del crecimiento y riesgo de adquirirlo. Las prevalencias de desnutrición observadas en Funza por el indicador talla/edad y peso/edad fueron inferiores a las reportadas en la ENDS 2000 para la subregión de Cundinamarca, que correspondían al $15,2 \%$ para el indicador talla/edad y al 6,5\% para el indicador peso/edad. En cuanto a la prevalencia de desnutrición aguda, en el municipio la desnutrición resultó ser mayor al valor de 0,8\% reportado por la ENDS 2000 para el departamento de Cundinamarca (61). Teniendo en cuenta los datos de la ENDS 2005, la prevalencia de desnutrición crónica y global en Cundinamarca fue 
Cuadro 6. Predictores de riesgo usados para buscar asociación estadística con deficiencia de hierro medida por ferritina, resultados estadísticos.

\begin{tabular}{|c|c|c|c|c|c|}
\hline \multicolumn{6}{|c|}{ Deficiencia de hierro } \\
\hline Variables & Predictor de riesgo & Valor de $p$ & $\begin{array}{c}\text { Razón de } \\
\text { prevalencias }\end{array}$ & $\begin{array}{c}\text { Intervalo de } \\
\text { confianza } 95 \%\end{array}$ & Ji cuadrado \\
\hline \multicolumn{6}{|c|}{ Sociodemográficas y de salud } \\
\hline Estrato socioeconómico & 102 & 0,512 & & & 1,339 \\
\hline No. de niños menores de 5 años & 20 más & 0,421 & & & 0,65 \\
\hline Edad de la madre & $<250>40$ & 0,380 & 0,83 & $0,53-1,28$ & 0,77 \\
\hline Escolaridad de la madre & primaria & 0,328 & & & 4,62 \\
\hline Escolaridad del padre & primaria & 0,001 & & & 20,32 \\
\hline Ocupación de la madre & ama de casa & 0,736 & 0,94 & $0,65-1,35$ & 0,11 \\
\hline Tenencia de la vivienda & arrendada & 0,939 & 1,01 & $0,71-1,45$ & 0,01 \\
\hline Tipo de vivienda & Inquilinato & 0,198 & 1,39 & $0,87-2,22$ & 1,65 \\
\hline Condiciones de salud del niño & enfermedad en el mes anterior & 0,028 & 0,60 & $0,38-0,96$ & 4,79 \\
\hline \multirow[t]{2}{*}{ Desparasitación } & $>1$ mes & 0,171 & 1,47 & $0,89-2,42$ & 1,87 \\
\hline & De alimentación & & & & \\
\hline Duración de la lactancia exclusiva & $<60>6$ meses & 0,145 & 0,76 & $0,53-1,09$ & 2,11 \\
\hline Recibió charlas de alimentación & No recibió charlas de alimentación & 0,466 & 0,68 & $0,24-1,94$ & 0,53 \\
\hline Es beneficiario de algún programa de & No es beneficiario de algún programa & & & & \\
\hline alimentación y nutrición & de alimentación y nutrición & 0,248 & 0,81 & $0,56-1,17$ & 1,33 \\
\hline Pajarilla, morcilla & consumió hace más de un mes & 0,082 & 1,36 & $0,96-1,92$ & 3,02 \\
\hline $\begin{array}{l}\text { Bofe, chorizo, pata, riñón, corazón, } \\
\text { hígado }\end{array}$ & consumió hace más de una semana & 0,426 & 1,16 & $0,81-1,64$ & 0,63 \\
\hline Carnes, embutidos y sardinas & consumió hace más de un día & 0,419 & 1,15 & $0,81-1,64$ & 0,65 \\
\hline \multirow[t]{2}{*}{ Alimentos fortificados } & consumió hace más de un día & 0,138 & 1,37 & $0,89-2,12$ & 2,19 \\
\hline & Antropométricas & & & & \\
\hline Talla para la edad & Retraso en el crecimiento < 2 DS & 0,118 & 1,52 & $0,95-2,42$ & 2,44 \\
\hline
\end{tabular}

similar al valor encontrado en Funza; para Cundinamarca la desnutrición crónica fue de $9,4 \%$ y la desnutrición global, de $3,6 \%$, en tanto que la desnutrición aguda en Funza es mayor al 0,6\% señalado por la ENDS 2005 para el departamento de Cundinamarca (31). El problema por desnutrición aguda parece entonces ser mayor al de otras zonas del departamento de Cundinamarca.

Aunque con algunas diferencias porcentuales, los resultados de desnutrición en los tres tipos de institución a los que asisten los preescolares en Funza señalan que existe población vulnerable de desnutrición en todos ellos, lo que puede deberse a que todos los niños pertenecen a un estrato socioeconómico bajo (cuadro 3).

El riesgo de desnutrición, así como la deficiencia misma, probablemente contribuyen a la deficiencia en micronutrientes encontrada en la población de niños porque, como mencionan algunos estudios, la carencia de macronutrientes altera el mecanismo biológico por medio del cual se metabolizan los micronutrientes, y también debido a factores de riesgo comunes para ambos tipos de deficiencia nutricional como el inadecuado consumo de alimentos fuente, la presencia de enfermedades y pertenecer a un estrato socioeconómico bajo $(27,29,30)$. Nuestros resultados, sin embargo, concuerdan con otros estudios en preescolares en los que existen problemas moderados de anemia y deficiencia de vitamina $A$, sin diferencias significativas entre niños desnutridos moderados y eutróficos (62).

Se encontraron preescolares afectados por parasitismo intestinal, en la mayoría de tipo no patógeno. El parasitismo hallado no se asoció con anemia y deficiencia de vitamina A probablemente porque la frecuencia de los parásitos que producen sangrado intestinal o que están relacionados con la disminución de las concentraciones de vitamina A es mínima o no están presentes; únicamente se halló Giardia duodenalis asociada con alteraciones del estado nutricional y a deficiencia de micronutrientes porque interfieren en la digestión, en la absorción y en el metabolismo de los nutrientes (13,63-66). Sin embargo, un inconveniente que se presentó en el análisis de 
parasitismo es que las muestras recolectadas estuvieron por debajo del número de muestras que se estimaron inicialmente.

La asociación de anemia con vivir en inquilinato o no pertenecer a un programa de alimentación y la de deficiencia de vitamina $A$ con enfermedad sugiere dos aspectos importantes para el riesgo de deficiencia de micronutrientes. Los dos primeros están relacionados con situación socioeconómica y el tercero con morbilidad. De estos dos aspectos se podrían definir predictores de riesgo más sensibles, por ejemplo, características específicas de los programas de ayuda alimentaria, en el que se indague sobre la aceptación por parte del niño de los alimentos ofrecidos en el programa, la distribución intrafamiliar de alimentos que se conceden para el hogar, los conocimientos de la familia sobre alimentación saludable, el tiempo en el programa, la continuidad y las causas de deserción. Con respecto a la participación en programas de alimentación, un estudio en preescolares de Chile sugiere que no pertenecer a un programa de apoyo alimentario puede ser un riesgo para la deficiencia de hierro. El estudio señala el éxito de los programas de fortificación de los alimentos con hierro en la prevención de la anemia ferropriva y explica que la continuación de tales programas de intervención se justifica mientras continúe el bajo aporte de hierro de la dieta habitual de la población, especialmente de aquella de más bajo nivel socioeconómico (67).

La inexistencia de asociación estadística entre deficiencia de hierro, anemia y deficiencia de vitamina $A$ y los otros factores de riesgo presentes en la población, tales como ingreso familiar bajo, vivienda en arriendo, prácticas inadecuadas de lactancia materna y de alimentación cuando el niño está enfermo y la circunstancia de que la totalidad de los preescolares pertenece a un estrato socioeconómico bajo, no invalida su posible asociación con la deficiencia nutricional. El resultado probablemente se debe a que, aunque

Cuadro 7. Predictores de riesgo usados para buscar asociación estadística con deficiencia de vitamina A medida por retinol en suero, resultados estadísticos.

\begin{tabular}{|c|c|c|c|c|c|}
\hline \multicolumn{6}{|c|}{ Deficiencia de vitamina A } \\
\hline Variables & Predictor de riesgo & Valor de $p$ & $\begin{array}{c}\text { Razón de } \\
\text { prevalencias }\end{array}$ & $\begin{array}{l}\text { Intervalo de } \\
\text { confianza }\end{array}$ & Ji cuadrado \\
\hline \multicolumn{6}{|c|}{ Sociodemográficas y de salud } \\
\hline Estrato socioeconómico & 102 & 0,902 & & & 0,207 \\
\hline No. de niños menores de 5 años & 20 más & 0,626 & & & 0,24 \\
\hline Edad de la madre & $<250>40$ & 0,655 & 0,91 & $0,59-1,40$ & 0,20 \\
\hline Escolaridad de la madre & primaria & 0,138 & & & 2,19 \\
\hline Escolaridad del padre & primaria & 0,167 & & & 7,80 \\
\hline Ocupación de la madre & ama de casa & 0,874 & 0,97 & $0,67-1,40$ & 0,02 \\
\hline Tenencia de la vivienda & arrendada & 0,235 & 1,24 & $0,87-1,77$ & 1,40 \\
\hline Tipo de vivienda & inquilinato & 0,723 & 1,1 & $0,64-1,92$ & 0,12 \\
\hline Condiciones de salud del niño & enfermedad en el mes anterior & 0,045 & 1,52 & $1,00-2,31$ & 3,99 \\
\hline Desparasitación & $>1$ mes & 0,732 & 0,87 & $0,39-1,95$ & 0,12 \\
\hline \multicolumn{6}{|c|}{ De alimentación } \\
\hline Duración de la lactancia exclusiva & $<60>6$ meses & 0,527 & 0,88 & $0,59-1,31$ & 0,40 \\
\hline Suplementación con emulsión de Scott & No toma hace un año & 0,626 & 0,1 & $0,61-1,34$ & 0,24 \\
\hline Recibió charlas de alimentación & No recibió charlas de alimentación & 0,718 & 1,14 & $0,57-2,27$ & 0,13 \\
\hline $\begin{array}{l}\text { Es beneficiario de algún programa de } \\
\text { alimentación y nutrición }\end{array}$ & $\begin{array}{l}\text { No es beneficiario de algún programa } \\
\text { de alimentación y nutrición }\end{array}$ & 0,571 & 0,90 & $0,62-1,30$ & 0,32 \\
\hline Hígado & consumió hace más de un mes & 0,927 & 1,02 & $0,71-1,46$ & 0,01 \\
\hline Huevo & consumió hace más de una semana & 0,313 & 1,21 & $0,83-1,79$ & 1,02 \\
\hline Lácteos & consumió hace más de un día & 0,800 & 1,05 & $0,73-1,51$ & 0,06 \\
\hline Alimentos enriquecidos & consumió hace más de un día & 0,445 & 0,86 & $0,58-1,26$ & 0,58 \\
\hline Complementos nutricionales & consumió hace más de un mes & 0,467 & 1,15 & $0,8-1,65$ & 0,53 \\
\hline \multicolumn{6}{|c|}{ Antropométricas } \\
\hline Talla para la edad & Retraso en el crecimiento $<2$ DS & 0,819 & 1,08 & $0,57-2,03$ & 0,05 \\
\hline
\end{tabular}


la asociación de estos factores con la deficiencias de micronutrientes está ampliamente demostrada en distintos estudios y en diferentes grupos de población $(10,11,13,16,19,20,23,25)$, el grado de participación en la deficiencia es inferior al observado en otras poblaciones; es esto lo que precisamente valida el hecho de que se evalúen estos mismos factores en distintas poblaciones; es decir, la no asociación se debe a la misma concepción de riesgo que indica un aumento en la probabilidad de que se sufra una enfermedad, pero no necesariamente que debe producirse (68). El resultado también pudo verse influenciado por el tipo de estudio realizado, el cual no corresponde a un diseño de casos y controles, o porque tal vez es necesario determinar indicadores más específicos para medir la influencia de los factores de riesgo presentes en esta población.

La no asociación estadística de los factores de riesgo hallados en la población de preescolares y la deficiencia de micronutrientes tampoco se invalida por el hecho de que puedan ser factores asociados a la deficiencia en otros grupos de población del país o de otras zonas, ya que existen grandes diferencias entre las poblaciones que hacen que la participación de un factor de riesgo en la presencia de una enfermedad sea diferente entre ellas (68). En Costa Rica se ha encontrado que la baja escolaridad de la madre, conjuntamente con un alto número de miembros de la familia, influye significativamente en la cantidad de vitamina A disponible para el preescolar. Según la Organización Mundial de la Salud, la combinación de estos factores se asocia con una alta vulnerabilidad a la carencia de vitamina $A$, situación que ha sido ampliamente demostrada en diferentes regiones latinoamericanas (57). En la población chilena La Pintana se encontró que la deficiencia de hierro no es un problema prevalente en los preescolares que asisten a jardines infantiles o centros abiertos: sólo 5,2\% de los niños tenía un agotamiento de las reservas de hierro y ninguno de ellos presentó anemia ferropriva. La explicación dada se basa en el impacto de los programas de fortificación de alimentos y probablemente también en el aumento del nivel socioeconómico de la población en los últimos años; sin embargo, no se descarta que en otros sectores de la misma comunidad, con condiciones económicas menos favorables, sí pueda existir la deficiencia (67).

Es probable que existan otros factores de riesgo que no se evaluaron en el estudio y que eventualmente podrían contribuir al riesgo para la deficiencia de hierro y vitamina A presente en la población de niños de Funza. En la literatura científica se mencionan riesgos asociados a la presencia de contaminación ambiental; por ejemplo, en algunos estudios se ha descrito que en niños de 1 a 18 años la exposición al plomo puede estar asociada con anemia porque el metal utiliza el mismo mecanismo que media la absorción del hierro (69-72).

En conclusión, en la población estudio se presenta alta prevalencia de anemia y deficiencia de hierro mientras que la deficiencia de vitamina $A$ no es tan prevalente; además se observa desnutrición crónica, global y aguda. Los factores de riesgo para las deficiencias de micronutrientes se centran en las condiciones socioeconómicas de la familia, las prácticas inadecuadas de alimentación y de lactancia materna y la morbilidad. Excepto las variables de vivir en inquilinato, no pertenecer a un programa de ayuda alimentaría y de morbilidad, las otras variables de riesgo consideradas no mostraron asociación con las deficiencias de micronutrientes encontradas en esta población, no obstante, podrían influir para que se presente la deficiencia al igual que sucede en otras poblaciones.

Se sugiere indagar por anemia nutricional relacionada con ácido fólico y vitamina $B_{12}$, estudiar con mayor detalle el consumo de alimentos de la población e investigar sobre la presencia de otros posibles factores de riesgo para las deficiencias de estos micronutrientes en esta población. Adicionalmente, sería conveniente incluir en los programas de ayuda alimentaria a la población en riesgo y a los preescolares que asisten a colegios privados del sector, los cuales siguen siendo niños y niñas en situación vulnerable porque igualmente pertenecen a un estrato socioeconómico bajo, con condiciones de vida muy similares a las de los preescolares atendidos en los otros dos tipos de institución. 
Es necesario fortalecer otros programas orientados a mejorar la situación nutricional de la población; las estrategias deben incluir vigilancia epidemiológica, promoción de estilos de alimentación saludable, prevención de la enfermedad y, si es necesario, recurrir a la suplementación nutricional en los grupos más afectados. La desnutrición y las deficiencias de los micronutrientes presentes en la población podrían también reducirse con estrategias encaminadas a mejorar la situación socioeconómica de la familia.

\section{Agradecimientos}

Los autores agradecen a la Secretaría de Salud del Municipio de Funza, que colaboró en la ejecución y desarrollo del proyecto suministrando los reactivos para la determinación de ferritina y apoyo logístico para la recolección de la información en la fase de campo. Las autoras también agradecen a la comunidad educativa de las instituciones participantes y a los Hogares Comunitarios del ICBF del Municipio de Funza.

\section{Conflicto de intereses}

Las autoras manifiestan que no existen conflictos de intereses en la elaboración y ejecución de este proyecto.

\section{Financiación}

Este proyecto fue financiado por el Instituto Nacional de Salud y recibió apoyo de la Secretaría de Salud del Municipio de Funza.

\section{Referencias}

1. Bowman B, Russell R. Conocimientos actuales sobre nutrición. 8 ed. Washington DC: OPS; 2003. p.201-76.

2. Repillo P. Nutrición Humana y Dietética. Madrid: Marbán S.L; 2001. p.20-2.

3. Mahan K, Escott-Stump S. Nutrición y dietoterapia de Krause. Novena edición. México, D.F: McGraw-Hill Interamericana; 1998. p.81-3,142-3.

4. The World Bank Group. Enriqueciendo la vida: lucha contra la malnutrición por deficiencia de vitaminas y minerales en los países en desarrollo. Serie el desarrollo en la práctica. 1st ed. Washington: World Bank; 1996. p.3-10.

5. Sommer A. Vitamin A deficiency and its consequences: a field guide to their detection and control. Third edition. Geneva: World Health Organization; 1995.
6. World Health Organization. Iron deficiency anaemia: assessment, prevention and control. A guide for programme managers. Geneva: World Health Organization; 2001 (document WHO/NHD/01.3).

7. Yip R. Iron deficiency: contemporary scientific issues and international programatic approaches. J Nutr 1994;124(Suppl. 8):1479-90.

8. PAHO. La salud en las Américas, edición 2002, Washington, D.C.: PAHO; 2002. p.12-3.

9. Ministerio de Salud, Instituto Nacional de Salud. Deficiencia de hierro, vitamina A y prevalenacia de parasitismo intestinal en la población infantil y anemia nutricional en mujeres en edad fértil, Colombia 19951996. 1ed. Bogotá; INS; 1998. p.25-46.

10. Neuman NA, Tanaka OY, Szarfarc SC, Guimaraes PR, Victora CG. Prevalence and risk factors for anemia in Southern Brazil. Rev Saude Publica 2000; 34:56-63

11. Khandait D, Vasudeo N, Zodpey S, Kumbhalkar D. Risk factor for subclinical vitamin A deficiency in children under the age of 6 years. J Trop Pediatr 2000;46:239-40.

12. Restrepo MT. Estado nutricional y crecimiento físico. Medellín: Universidad de Antioquia; 2000. p.154

13. Friis $\mathbf{H}$, Mwaniki D, Omodi B, Muniu E, Magnussen $\mathbf{P}$, Geissler W et al. Serum retinol concentrations and schistosoma mansoni, intestinal helminths, and malarial parasitemia: a cross-sectional study in kenyan preschool and primary school children. Am J Clin Nutr 1997;66:665-71.

14. Semba R, Bloem M. Nutrition and health in developing countries. New Jersey: Humana Press; 2001. p.267306, 327-42.

15. Mele L, West K, Kusdion O, Pandji A, Nendrawati $\mathbf{H}$, Tilden $\mathbf{R}$ et al. Nutrition and household risk factors for xerophthalmia in Aceh, Indonesia: A case-control study. Am J Clin Nutr 1991;53:1460-5.

16. Castejón VH, Ortega P, Díaz M, Amaya D, Gómez G, Ramos $\mathbf{M}$ et al. Prevalencia de deficiencia subclínica de vitamina $A$ y desnutrición en niños marginales de Maracaibo, Venezuela. Arch Latinoam Nutr 2001; 51:25-32.

17. Villamor E, Mbise R, Spiegelman D, Ndossi G, Fawzi WW. Vitamin A supplementation and other predictors of anemia among children from Dar Es Salaam, Tanzania. Am J Trop Med Hyg 2000;62:590-7.

18. Mira M, Alperstein G, Karr M, Kanmuthugala G, Causer D, Niec A et al. Haem iron intake in 12-36 month old children depleted in iron: Case control study. BMJ 1996;312:881-3.

19. Rosen DS, Sloan NL, del Rosario A, de la Paz TC. Risk factors for vitamin A deficiency in rural areas of the Philippines. J Trop Pediatr 1994;40:82-7. 
20. Kjolhede CL, Stallings RY, Dibley MJ, Sadjimin T, Dawwiesah S, Padmawati S. Serum retinol levels among preschool children in central Java: demographic and socioeconomic determinants. Int $\mathrm{J}$ Epidemiol 1995;24:399-403.

21. Galobardes B, Moravia A, Bernstein M. Diet and socioeconomic position: Does the use of different indicators matter? Int J Epidemiol 2001;30:334-40.

22. Agudelo GM, Cardona OL, Posada M, Montoya MN, Ocampo N, Marin CM et al. Prevalence of iron-deficiency anemia in schoolchildren and adolescents, Medellín, Colombia, 1999. Rev Panam Salud Pública 2003;13:376-86.

23. Johns T, Booth L, Kuhnlein V. Factors influencing vitamin $A$ intake and programmes to improve vitamin $A$ status. Food Nutr Bull 1992;14:20-33.

24. OPS/OMS. Informe de una reunión de consulta sobre uncinariasis y anemia en niñas y mujeres serie HCTAIEPI-18. Washington DC: OPS; 2000. p.42.

25. Ferreira M, Souza W, Perez E, Lapa T, Carvalho A, Furtado A et al. Intestinal helminthiases and anaemia in youngsters from Matriz da Luz district of Sao Lorenco da Mata, state of Pernambuco, Brasil. Mem Inst Oswaldo Cruz 1998;3:289-93.

26. Chen WA, Lesperance L, Bernstein H. Screening for iron deficiency. Pediatr Rev 2002;23:171-8.

27. Organización de las Naciones Unidas para la Agricultura y la Alimentación FAO. Sexta Encuesta Alimentaria Mundial. Primera edición. Roma: FAO; 1996. p.4.

28. Olsen A, Magnussen P, Ouma JH, Andreassen J, Friis $\mathbf{H}$. The contribution of hookworm and other parasitic infection to hemoglobin and iron status among children and adults In Western Kenya. Trans R Soc Trop Med Hyg 1998;92:643-9.

29. Waterlow J C. Malnutrición proteíco energética. Primera edición. Washington: OPS; 1996. p.501.

30. Food and Agriculture Organization of the United Nations (FAO) and International Life Sciences Institute (ILSI). Preventing micronutrient malnutrition a guide to food-based approaches - Why policy makers should give priority to food-based strategies, chapter 3, 5 . Washington D.C: ILSI Press; 1997.

31. PROFAMILIA Encuesta Nacional de Demografía y Salud ENDS, 2005. [Consulta: 18 octubre de 2006]. Disponible en: http://www.profamilia.org.co/encuestas/ index ends.

32. ICBF. Encuesta Nacional de la Situación Nutricional en Colombia, ENSIN 2005. [Consulta: 18 octubre de 2006]. Disponible en: http://www.icbf.gov.co/espanol/ ENSIN_PAGINA\%20WEB\%202005.pdf

33. Organización Mundial de la Salud. Manual de bioseguridad en el laboratorio. 3 edición. Ginebra: OMS; 2005.
34. Organización de las Naciones Unidas para la Agricultura y Alimentación FAO. Latham MC. Colección FAO: Alimentación y nutrición. 1 ed. № 29. Roma: FAO; 2002.

35. Lartey A, Manu A, Brown KH, Dewey KG. Predictors of micronutrient status among six- to twelve-month-old breast-fed Ghanaian infants. J Nutr 2000;130:199-207.

36. Stoltzfus RJ, Chwaya HM, Albonico M, Schulze KJ, Savioli L, Tielsch JM. Ferritin erythrocyte protoporphyrin and hemmoglobin are valid indicators of iron status of school children in a malaria-holoendemic population. J Nutr 1997;127:293-8.

37. Olivares M, Walter T, Cook JD, Hertrampf E, Pizarro F. Usefulness of serum transferrin receptor and ferritin in diagnosis of iron deficiency in infancy. Am J Clin Nutr 2000;72:1191-5

38. Karpacheva V. A micromethod for the determination of carotene and vitamin A in whole blood. Biull Eksp Biol Med 1964;58:120-1.

39. De Araujo CR, Flores H. Improved spectrophotometric vitamin A assay. Clin Chem 1978;24:386.

40. Underwood BA. Hypovitaminosis A: International programmatic issues. J Nutr 1994;124(Suppl. 8) 1467S-72S

41. International Vitamin A Consultative Group. Biochemical methodology for the assessment of vitamin A status. 1ed. Washington DC: Nutrition Foundation; 1982.

42. Arroyave G, Chichester C, Flores H, Glover G, Mejia LA, OIson JA et al. Biochemical methodology for the assessment of vitamin A status: A report of the International Vitamin A Consultative Group. Washington DC: The Nutrition Foundation; 1982.

43. Flores H, Azevedo MN, Campos FA, Barreto-Lins MC, Cavalcani AA, Salcano AC et al. Serum vitamin A distribution curve for children aged 2-6 y known to have adequate vitamin A status: a reference population. Am J Clin Nutr 1991;54:707-11.

44. Organización Panamericana de la Salud. Indicadores para determinar la carencia de vitamina A y su aplicación en el seguimiento y la evaluación de los programas de intervención. OMS/NUT: Washington D.C.; 1996.

45. Duque S, Guerrero R, Nicholls RS, Lopez MC. Examen coproparasitológico en niños: comparación de resultados obtenidos por dos métodos en dos instituciones de Santa Fe de Bogotá. Biomédica 1994;14:39-47.

46. Ritchie LS. An ether sedimentation technique for routine stool examination. Bull US Army Med Dep 1948;8:326.

47. World Health Organization. Physical status: the use and interpretation of anthropometry. Report of a WHO 
Expert Committee. Geneva: World Health Organization; 1995. (Technical Report Series, No. 854).

48. De Onís M, Monteiro C, Akré J, Clugston C. The worldwide magnitude of protein-energy malnutrition: an overview from the WHO Global Database on Child Growth. Bull World Health Organ 1993;71:703-12.

49. Organización Mundial de la Salud. Medición del cambio del estado nutricional. Ginebra: OMS; 1983.

50. Acevedo E, Sanabria M, Delgadillo J, Castillo Durán. Kwashiorkor y marasmo-kwashiorkor en niños hospitalizados. Pediatría 2004;31:16-22.

51. Ministerio de Salud Pública, Programa de seguridad alimentaría y nutricional, programa de inmunizaciones, Organización Panamericana de la salud. Uso de las referencias para el crecimiento. [Consultado: 14 de noviembre de 2006]. Disponible en: http:// www.paho.org/Spanish/AD/FCH/NU/MEX04_ Guatemala.pdf

52. Atalah E, Urteaga C, Rebolledo A, Delfín S, Ramos R. Prevalencia de obesidad en escolares de la región de Aysén. Rev Chil Pediatr 1999;70:208-14.

53. Rivera C, Guardia S, Cornejo E, Young T. Índice de riesgo nutricional (IRN) en lactantes: aplicación y comparación de un instrumento de evaluación. Rev Chil Nutr 2002;2:126-36.

54. Sancho E. Ministerio de Salud. Instituto Costarricense de Investigación y Enseñanza en Nutrición y Salud, Caja Costarricense de Seguro Social, Ministerio de Educación Pública. Desarrollo de comunidades centinela sobre alimentación y nutrición. Antropometría. Convenio de Cooperación Ministerio de Salud-UNICEF Área de Vigilancia Nutricional Costa Rica. [Consultado: 14 de noviembre de 2006]. Disponible en: http:// www.ministeriodesalud.go.cr/Web\%20Direccion\% 20Investigacion/Archivos/Centiant.pdf

55. Abdullah M, Ahmed L. Validating a simplified approach to the dietary assessment of vitamin A intake in preschool children. Eur J Clin Nutr 1993;47: 115-22.

56. Instituto Colombiano de Bienestar Familiar, Subdirección de Nutrición, Producción y Distribución de Alimentos. Tabla de composición de alimentos colombianos. 5 ed. Bogotá: Sección de Divulgación ICBF; 1988.

57. Carvajal F, Alfaro C, Monge R. Deficiencia de vitamina A en niños preescolares: ¿Un Problema reemergente en Costa Rica? Arch Latinoam Nutr 2003;53:267-70.

58. Abraham K, Muller C, Gruters A, Wahn U, Schweigert F. Minimal inflammation, acute phase response and avoidance of misclassification of vitamin $A$ and iron status in infants-importance of a highsensitivity C-reactive protein (CRP) assay. Int J Vitam Nutr Res 2003;73:423-30.
59. Olivares AB, Gaspar R, Bernal M, Martínez C Periago M. Estimación de la ingesta y necesidades de enriquecimiento de folatos y ácido fólico en alimentos. Arch Latinoam Nutr 2005;55:5-14.

60. Rodríguez A, Guamán G, Nelson D. Estado nutricional de los niños de cinco provincias del Ecuador con respecto a la vitamina A. Bol Oficina Sanit Panam 1996;120:117-24.

61. PROFAMILIA. Encuesta Nacional de Demografía y Salud ENDS, 2000. [Consultada: 19 octubre de 2006]. Disponible: http://www.profamilia.org.co/encuestas/ index_ends.

62. Abreu J, Borno S, Montilla M, Dini E. Anemia y deficiencia de vitamina $A$ en niños evaluados en un centro de atención nutricional de Caracas. Arch Latinoam Nutr 2005;55:226-34.

63. Zetina A, García JO, Rodríguez D, Coronado F, Bran JL. Relación del parasitismo intestinal y bajo peso para la talla: estudio piloto en 338 niños de áreas marginales de la ciudad de Guatemala. Rev Co Méd Cir Guatem 1998;8:11-2.

64. Muniz, Junqueira, Oliveira E. Relationship between protein-energy malnutrition, vitamin $A$, and parasitosis in children living in Brasília. Rev Soc Bras Med Trop 2002;35:133-41.

65. Hesham MS, Edariah AB, Norhayati M. Intestinal parasitic infections and micronutrient deficiency: a review. Med J Malaysia 2004;59:284-93.

66. Sackey ME, Weigel MM, Armijos RX. Predictors and nutritional consequences of intestinal parasitic infections in rural Ecuadorian children. J Trop Pediatr 2003;49:17-23.

67. Díaz M, Guerra P, Campos M. Prevalencia de deficiencia de hierro en preescolares de la comuna La Pintana. Rev Chil Nutr 2002;29:10-3.

68. Alvarez H, Alvarez A. Investigación y epidemiología. 1 ed. Santa Fe de Bogotá: Ecoe Ediciones; 1998. p.175-8.

69. Díaz RG, Perez ZA, Uribe HR. Frecuencia de anemia por deficiencia de hierro y su relación con el plomo sanguíneo. Bol Med Hosp Infant Mex 2001;58:505-15.

70. Agency for Toxic Substances and Disease Registry (ATSDR). Toxicological Profile for Lead. Atlanta, U.S: Public Health Service, ATSDR; 1990.

71. Aschengrau A, Beiser A, Bellinger D, Copenhafer D, Weitzman M. The impact of soil lead abatement on urban children's blood lead levels: phase II results from the Boston lead-in-soil demonstration project. Environ Res 1994;67:125-8.

72. Nathan DG, Oski FA. Hematology of infancy and childhood. 4th ed. Philadelphia: Ed. WB Saunders Company; 1990. p.346-472. 